\title{
Variação das preposições em verbos de movimento
}

\author{
Maria José Blaskovski VIEIRA *
}

Resumo: A tradição gramatical brasileira, da mesma forma que a norma européia, prescreve a seleção de preposições direcionais para verbos como "chegar", "vir", "levar", "ir". No entanto, na fala coloquial, é a preposição locativa "em" que se realiza juntos a esses verbos. Neste trabalho, pretende-se discutir o processo de mudança que atinge essas preposições, utilizando-se os fundamentos teóricos da Teoria da Variação. Busca-se, através de uma análise variacionista, identificar os fatores linguísticos e extralinguísticos que condicionam a escolha da preposição que rege verbos de movimento. A análise quantitativa foi feita com base em 39 entrevistas de falantes das cidades de Porto Alegre, Florianópolis e Curitiba.

Palavras-chave: Verbos de movimento; Variação; Regência verbal.

Abstract: The Brazilian grammatical tradition, as well as the European norm, prescribes the selection of directional prepositions to verbs like: "arrive", "come", "carry", "go". However, in the colloquial speech, it is the locative preposition "in" which is accomplished together with these verbs. This paper aims to discuss the process of change that affects these prepositions, making use of the theoretical processes from Theory of Variation. It is searched, through a variationist analysis, identify the linguistic and extra linguistic factors that condition the choice of the preposition that governs verbs of movement. Quantitative analysis was based

\footnotetext{
* Doutorado em Linguística e Letras pela Pontifícia Universidade Católica do Rio Grande do Sul (1997). Docente da Faculdade de Letras da Universidade Federal de Pelotas (RS). Contato: blaskovskivi@yahoo.com.br.
} 
on 39 interviews of speakers from three cities: Porto Alegre, Florianópolis and Curitiba.

Keywords: Verbs of movement; Variation; Verbal regency.

\section{Introdução}

No Português Brasileiro, assim como em Moçambique e Angola, ${ }^{1}$ constata-se a alternância de preposições que regem verbos de movimento. A tradição gramatical brasileira, da mesma forma que a norma européia, prescreve a seleção de preposições direcionais para verbos como chegar, vir, ir. No entanto, na fala coloquial, a preposição locativa $e m$ alterna com as preposições al para com esses verbos.

Neste trabalho, pretende-se apresentar resultados de análise quantitativa que aponta fatores linguísticos e extralinguísticos condicionadores da regência dos verbos de movimento ir, vir, levar e chegar. Para tanto, foram analisadas amostras de fala de habitantes das três capitais dos Estados do sul do país. Partiu-se da ideia, para o seu desenvolvimento, de que as variações linguísticas observáveis podem resultar de condicionamentos linguísticos e extralinguísticos.

\section{A classe das preposições}

De maneira geral, as preposições não têm tido um tratamento adequado nas gramáticas, uma vez que as descrições são fragmentadas e esparsas, localizadas em partes não relacionadas entre si. Além disso, é comum, na maior parte das gramáticas, a falta de referência ao aspecto semântico das preposições.

\footnotetext{
${ }^{1}$ Gonçalves (1996 e 2000) mostra que um dos aspectos que caracterizam o Português moçambicano e também o angolano é o uso de preposições locativas regendo verbos de movimento.
} 
Cunha (1978) analisa as preposições do ponto de vista semântico, definindo-as como a palavra invariável que relaciona termos de uma oração, de tal modo que o sentido do primeiro, a que chama de antecedente, é explicado ou completado pelo segundo, chamado de consequente. A relação que se estabelece entre as palavras ligadas por meio de preposição pode exprimir movimento ou uma situação resultante do movimento. Tanto o movimento como a situação podem ser considerados em referência a espaço, tempo ou noção.

Apesar de as preposições apresentarem uma grande variedade de sentidos em contextos diversos, é possível definir, ainda de acordo com Cunha, uma significação fundamental, marcada pela expressão de movimento ou de situação resultante e aplicável aos campos espacial, temporal e nocional.

As preposições $a$, em e para, por exemplo, tanto têm sentido de movimento quanto de situação: o sentido de movimento expressa aproximação de um limite ( $a$ e para) e tendência para uma posição de contato ou de interioridade (na preposição em). Já o sentido de situação expressa coincidência, concomitância (preposição $a$ ), posição no interior, dentro de limites (preposição em) e finalidade, direção (preposição para).

\subsection{O valor semântico das preposições}

De um ponto de vista tradicional, não há divergência a respeito do status da preposição como unidade funcional que relaciona elementos na sentença. No entanto, o fato de serem unidades funcionais não implica que sejam desprovidas de valor semântico. ${ }^{2}$ Esse valor semântico só se atualiza ou se manifesta

\footnotetext{
${ }^{2} \mathrm{O}$ valor semântico das preposições pode ser comprovado a partir da análise da diferença de sentido das frases a seguir, retiradas de Travaglia (2003, p. 186): João falou de Maria; João falou para Maria; João falou por Maria; João falou perante Maria; João falou sobre Maria; João falou ante Maria; João falou a Maria; João falou junto a Maria; João falou com a Maria; João falou em Maria.
} 
em contextos sintáticos determinados, já que é dependente do valor semântico de outros itens da sentença (KLEPPA, 2005).

Para Kleppa (2005, p. 72), quanto mais esvaziado for o conteúdo semântico de uma preposição, mais dependente ela se torna do conteúdo semântico do termo que a seleciona, ou seja, ela poderá ocorrer em vários contextos sintáticos, já que seu valor semântico não é restrito ou específico, mas emerge em combinação com outros termos.

Há preposições que têm um valor semântico mais transparente; são aquelas não gramaticalizadas e que preservam seu conteúdo semântico (até, contra, desde, entre, sem, sob); outras, que têm um valor semântico opaco, são as preposições mais gramaticalizadas (a, com, de, em, para, por). Tais preposições caracterizam-se por possuírem valor semântico altamente esvaziado; poderem funcionar como introdutoras tanto de argumentos quanto de adjuntos; poderem ser amalgamadas com outros elementos linguísticos $(a+a, e m+a$, por $+a$, $d e+a)$ e por serem mais frequentes que as menos gramaticalizadas.

Castilho (2004) trabalha com a idéia de que as preposições têm um sentido prototípico que corresponde às categorias semântico-cognitivas de posição no espaço, deslocamento no espaço, distância no espaço e movimento, sendo que a categoria espaço pode ser descrita nos eixos horizontal, vertical e transversal. Com o uso, no entanto, tal sentido prototípico se modifica, tornando-se mais abstrato. ${ }^{3}$

Assim, por exemplo, o sentido prototípico da preposição $a$ é o de expressar, de forma mais genérica, a indicação da direção

\footnotetext{
${ }^{3}$ De acordo com Pontes (1992, p. 8), as preposições modificam-se primeiro em seu uso literal, ou seja, de espaço, mas perduram no uso metafórico. Assim, a preposição "a" já não é mais usada na maioria das acepções de espaço na língua coloquial, tendo sido substituída por "em" e "para", mas continua sendo um pouco mais usada quando indica tempo. Por exemplo, não se diz mais que a comida está à mesa, mas sim "na mesa". Mas ainda se diz "às dez horas".
} 
de um determinado movimento. Daí ser ela amplamente utilizada para a expressão de direção não só no espaço, mas também no tempo e em sentido nocionais diversos. Da mesma forma, para alterna com $a$ na expressão de direção. De formação tardia no latim vulgar, resultante da aglutinação de per $+a d$, "marcava um percurso com a direção definida” (CÂMARA Jr., 1975, p. 179).

Já a preposição $\mathrm{em}$, em seu sentido prototípico, situa ou localiza um evento em um determinado lugar no espaço, noção que, atualmente, pode ser especificada por uma série de preposições ou de outros itens lexicais.

\subsection{As preposiçoes e os verbos de movimento}

De acordo com a tradição gramatical, os verbos de movimento ir, chegar, vir, devem ser empregados com a preposição $a$ ou para, uma vez que essas preposições carregam sentido de direção, sendo que a escolha de uma ou outra implica uma diferença sutil de sentido. No entanto, na língua falada, além dessas preposições, também é comum o uso de em acompanhando esses verbos.

1) a) Tenho que vir ao sítio hoje.

b) Tenho que vir para o sítio hoje.

c) Tenho que vir no sítio hoje.

2) a) João foi à praia no fim de semana.

b) João foi para a praia no fim de semana.

c) João foi na praia no fim de semana.

3) a) $O$ diretor chegou à repartição no horário combinado.

b) O diretor chegou na repartição no horário combinado.

Os usos destacados em 1a, 1b, 2a, 2b e 3a são previstos pela tradição gramatical e considerados padrão culto, enquanto os usos destacados em 1c, 2c e 3b são considerados não padrão. Há autores 
que interpretam tal alternância como uma variação ${ }^{4}$ linguística, condicionada por fatores linguísticos e extralinguísticos. Mollica (1996), por exemplo, realizou pesquisa, através da qual identificou fatores linguísticos que condicionam a escolha de uma ou outra dessas preposições empregadas com o verbo $i$.

O estudo de Mollica mostra que traços semânticos do locativo influenciam a escolha da preposição. Locativos que se referem a um espaço fechado, a um lugar cercado como cinema, shopping, estádio tendem a selecionar a preposição $\mathrm{em}$; enquanto locativos que se referem a um lugar aberto, como praia, parque tendem a selecionar as preposições $a /$ para.

Um outro fator relevante, apontado pelo estudo, é o grau de definitude do locativo: quanto mais definido, maior a possibilidade de o verbo ser empregado com a preposição em; quanto mais indefinido, maior a possibilidade de ser empregado com as preposições $a$ ou para. Tais resultados apontam para o fato de que a maior ou menor integração entre preposição e locativo é dependente de características semânticas do locativo.

\section{Aspectos metodológicos}

Para realização deste estudo, a partir das variáveis sociais, foram selecionadas, do Banco de Dados VARSUL, entrevistas de cada uma das capitais dos Estados da Região Sul: Porto Alegre, Florianópolis e Curitiba. ${ }^{5}$ Os resultados que são apresentados envolvem dados de 39 informantes, assim distribuídos: 12 de Curitiba, 12 de Florianópolis e 15 de Porto Alegre.

\footnotetext{
${ }^{4}$ Com base nos pressupostos da Teoria Gerativa, Farias (2006, p. 216) afirma que a alternância no uso das preposições $a$, para e em com verbos de movimento não pode ser tratada como um caso de variação linguística nos moldes labovianos, isso porque a mudança de uma preposição por outra não representa simplesmente formas diferentes de se dizer a mesma coisa, mas constitui uma variação léxico-sintática.

${ }^{5}$ Os resultados aqui apresentados são parciais e serão complementados com dados de mais nove informantes que ainda estão sendo codificados.
} 
Para a realização da análise dos dados que compõem o corpus desta pesquisa, após a sua codificação, foram utilizados programas computacionais que formam o pacote VARBRUL. Esse pacote de programas toma um conjunto de dados linguísticos e os organiza, de acordo com a variável dependente, em ambientes possíveis do ponto de vista linguístico e extralinguístico. Após o estabelecimento de tais contextos, o programa realiza um algoritmo que fornece informações estatísticas, na forma de pesos relativos, para cada fator condicionador da regra variável (BISOL; BRESCANCINI, 2002). A partir daí, são selecionadas, estatisticamente, as variáveis de maior relevância na aplicação da regra. Os dados coletados foram codificados de acordo com as variáveis a seguir e submetidos a tratamento estatístico com os programas do pacote VARBRUL, versão Goldvarb 2001 para ambiente Windows.

\subsection{Definição das variáveis}

Considera-se como variável dependente o uso da preposição a/para ${ }^{6}$ regendo verbos de movimento. Nesta pesquisa, trabalhase com a hipótese de que a variação no uso das preposições com verbos de movimento pode ser resultado de um afrouxamento, no plano conceptual, da relação entre a preposição e o verbo, por um lado, e do estreitamento da relação entre preposição e argumento do verbo ou adjunto, por outro lado. Portanto, a variação seria condicionada por fatores linguísticos.

As variáveis independentes, controladas nesta pesquisa, dividem-se em variáveis linguísticas e extralinguísticas. São variáveis linguísticas o tipo de verbo, configuração do espaço, grau de definitude e de determinaşão do locativo, traço semântico [士 permanência], existência de

\footnotetext{
${ }^{6}$ Neste trabalho, as preposições a/para são analisadas conjuntamente opondo-as a $\mathrm{em}$. Posteriormente, será feita análise em separado de $a \mathrm{e}$ para.
} 
elemento interveniente entre o verbo e a preposição e variáveis extralinguísticas sexo, escolaridade, idade e variável geográfica.

\subsubsection{Variáveis linguísticas controladas no estudo}

A pesquisa realizada por Mollica (1996) sobre o uso variável de preposições que regem o verbo ir sugeriu algumas das variáveis linguísticas a serem consideradas na presente análise, assim como as hipóteses que nortearam o trabalho.

\subsubsection{Tipo de verbo}

Por meio dessa variável, buscou-se verificar o comportamento dos verbos ir, vir, chegar e levar em relação a sua regência. Parte-se da hipótese de que o verbo ir ${ }^{7}$ apresenta comportamento variável, enquanto os verbos vir, chegar e levar apresentam pouca variação.

\subsubsection{Configuração de espaço}

De acordo com o que Mollica (1996) chamou configuração de espaço, referindo-se ao nome que ocupa posição de núcleo no SPres ligado ao verbo, foram controlados os traços semânticos do locativo [ \pm aberto]. O locativo que possui o traço [-aberto] tem como característica o fato de ser um lugar cercado, com uma entrada definida, com ou sem cobertura. Aquele que possui o traço [+aberto] caracteriza-se por não apresentar essas características ou por se referir a um lugar indefinido ou abstrato.

\subsubsection{Grau de definitude e de determinação do locativo}

Por meio da variável grau de definitude e de determinação do locativo, controlaram-se dois tipos de informações, o fato de

${ }^{7}$ Somente foram coletados dados em que o verbo ir tinha sentido pleno. 
os locativos terem referentes conhecidos ou facilmente identificáveis por parte do falante/ouvinte e o fato de serem precedidos por artigo definido ou pronome possessivo ou demonstrativo. Essas informações desdobraram-se em dois traços: [ \pm definido] e $[\underline{ \pm}$ determinante $]$. Assim, se o locativo tivesse como referente um nome conhecido do falante/ouvinte e fosse precedido de artigo definido, receberia os traços [+definido, +determinante]; se fosse precedido de artigo indefinido ou pronome indefinido e fosse desconhecido de um dos interlocutores, receberia os traços [-definido, +determinante]; se os nomes não fossem precedidos de um determinante e o referente fosse conhecido, receberia os traços [+definido, -determinante]; e se os nomes não fossem precedidos de determinantes e os referentes fossem vagos, desconhecidos do falante/ouvinte, receberiam os traços [-definido, -determinante].

\subsubsection{Traços [士permanência]}

Por meio dessa variável controlou-se, através da análise do contexto linguístico, a presença/ausência da ideia de permanência no local de destino. Quando não havia, no contexto, indicações claras da ideia de permanência, o fator utilizado deveria ser [-permanência].

\subsubsection{Distância entre o verbo e a preposição}

Essa variável teve como motivação a suposição de que a existência ou não de elemento interveniente entre o verbo e a preposição poderia condicionar a escolha dessa preposição. Assim, partiu-se da hipótese de que a ausência de elemento interveniente favoreceria o uso da preposição a/para, enquanto a presença de elementos intervenientes (um, dois, três ou mais) favoreceria o uso da preposição $\mathrm{em}$. 


\subsubsection{Variáveis extralinguisticas controladas no estudo}

Entre as variáveis sociais, foram controlados nessa pesquisa o gênero, a idade (de acordo com a estratificação feita no VARSUL, -50 anos e +50 anos), o grau de escolaridade (de acordo com a estratificação feita no VARSUL, -4 anos e +4anos), e a localização geográfica (Porto Alegre, Florianópolis e Curitiba).

\section{Apresentação e discussão dos resultados}

Os resultados apresentados inicialmente referem-se a uma rodada em que levar, vir, ir e chegar foram analisados conjuntamente, com o objetivo de verificar, através da análise quantitativa, o comportamento geral desses verbos em relação a sua regência. A seguir, são apresentados os resultados de rodada somente com o verbo $i$, definindo-se os fatores linguísticos e extralinguísticos que condicionam a emergência da variante com a preposição a/para ou da variante com a preposição em.

\subsection{Resultados gerais para os verbos de movimento}

Das nove variáveis propostas, foram selecionadas pelo programa quatro variáveis linguísticas e uma extralinguística, com uma frequência geral de aplicação de 56\%. Foram considerados relevantes para a emergência da variante com a preposição a/para o tipo de verbo, o traço [士permanência], a configuração do espaço, o grau de definitude e de determinação do locativo e a variável geográfica. Os resultados que passam a ser apresentados referem-se à variável traço [tipo de verbo], a primeira a ser selecionada pelo programa. 


\begin{tabular}{|l|c|c|c|}
\hline & Aplic/total & $\mathbf{\%}$ & Peso relativo \\
\hline levar & $22 / 25$ & 88 & 0,84 \\
\hline vir & $47 / 56$ & 83 & 0,74 \\
\hline ir & $227 / 391$ & 58 & 0,60 \\
\hline chegar & $2 / 58$ & 3 & 0,01 \\
\hline Total & $\mathbf{2 9 8 / 5 3 0}$ & $\mathbf{5 6}$ & \\
\hline Significância: 0.001 & \multicolumn{3}{|c|}{ Input: 0.573} \\
\hline
\end{tabular}

Quadro 1 - Tipo de verbo - valor de aplicação: preposição para

No Quadro 1, a primeira questão a considerar é a desproporção em relação ao número de dados de um verbo e de outro. De um total de 530 ocorrências de verbos de movimento, 391 envolveram a presença do verbo ir, enquanto o verbo levar teve somente 25 ocorrências. Em segundo lugar, verifica-se que levar e vir são verbos que apresentam valores altos de uso da preposição a/para, conforme indicam as frequências $88 \%$ e $83 \%$ e os pesos relativos 0,84 e 0,74 , respectivamente. Em somente três situações o verbo levar se fez acompanhar da preposição em e o verbo vir em nove situações. Já o verbo chegar, das 58 ocorrências, apresentou somente dois contextos com a preposição para, o que representa uma frequência de $3 \%$ e peso relativo 0,01 . Diferentemente do que ocorre com os outros verbos, ir mostra variação significativa, havendo preferência pelo uso da variante com a preposição a/para, conforme indica o peso relativo 0,60 .

É possível supor que os resultados para vir, levar e chegar estejam relacionados à sua própria semântica, por essa razão apresentam pouca variação. Nos verbos vir e levar, a idéia de deslocamento parece estar inserida no seu sentido e a preposição que dá conta desse sentido é justamente a preposição a/para. Já em chegar não é o processo de deslocamento, mas o seu fim, que faz parte da semântica do verbo e a preposição que dá conta desse sentido é a preposição $\mathrm{em}$. Já para o verbo $i$, a variação pode ser 
explicada a partir do que propõe Borba (1971): quando o falante usa a preposição em com os verbos de movimento, ele não está interessado em representar a direção do movimento em si, mas apenas a sua inclusão no ponto de chegada, como em ir no restaurante. ${ }^{8}$

A segunda variável selecionada pelo programa como relevante no processo de preservação/substituição da preposição que rege verbos de movimento foi a variável [ \pm permanência] cujos resultados são apresentados no Quadro 2.

\begin{tabular}{|l|c|c|c|}
\hline & Aplic/total & $\mathbf{\%}$ & Peso relativo \\
\hline [+permanência] & $160 / 203$ & 78 & 0,81 \\
\hline [-permanência] & $138 / 327$ & 42 & 0,29 \\
\hline Total & $\mathbf{2 9 8 / 5 3 0}$ & $\mathbf{5 6}$ & \\
\hline Significância: 0.001 & \multicolumn{2}{|c|}{ Input: 0.573} \\
\hline
\end{tabular}

Quadro 2 - Traço semântico [permanência] - valor de aplicação: preposição para

\footnotetext{
${ }^{8}$ Quando a/para ocorre com verbos de movimento, o sentido de direção nessas preposições manifesta-se com alguma nitidez. Isso significa que, mesmo sendo consideradas preposições altamente gramaticalizadas e, portanto, semanticamente esvaziadas, é possível que o sentido de direção que emerge quando elas estão acompanhadas de verbos de movimento seja decorrente da influência desses verbos sobre elas. Kleppa (2005, p.72) corrobora essa afirmação ao dizer que, quanto mais esvaziado for o conteúdo semântico de um item lexical, mais dependente do conteúdo semântico do termo que o seleciona. Portanto, o sentido da preposição a/para pode ser resultante da proximidade com o verbo de movimento que a selecionou.
} 
Observa-se no Quadro 2, que a escolha da preposição al para ${ }^{9}$ ou a sua substituição pela preposição em está relacionada à idéia de permanência ${ }^{10}$ no local expresso pelo SPrep. Isso é o que indicam os resultados acima. O peso relativo de 0,81 aponta que, em contextos em que a idéia de permanência está presente, há uma tendência de ser para a preposição que rege o verbo. Quando não há a idéia de permanência, em contextos como $A \dot{i}$, a gente foi pra capela rez̧ar, há uma tendência menor de uso da preposição para, como se pode perceber pelo peso relativo de 0,29.

Esses resultados estão parcialmente em consonância com os encontrados por Mollica (1996), uma vez que, em sua pesquisa, em todos os dados contendo a preposição $\mathrm{em}$ não houve nenhum caso de [+permanência]. ${ }^{11}$ Tal fato se explica tendo em vista que a análise referia-se somente ao verbo $\mathrm{i}$. No entanto, se forem considerados outros verbos, como chegar, vir, ainda que em um número pequeno de situações, são encontrados contextos em que a idéia de permanência está presente, no entanto a preposição que rege o verbo não é para e $\operatorname{sim} \mathrm{em}$.

9 Segundo Silva, (1989, p. 628), no português arcaico, por vezes a preposição $a$ expressa a permanência ou a situação resultante de um movimento para um ponto de chegada, o que também poderia ser expresso pela preposição $\mathrm{em}$.

${ }^{10}$ Para determinação da presença ou não da idéia de permanência levouse em conta o contexto de fala de onde foi retirado o dado com o verbo a ser analisado. Nos casos em que não estava claro se havia a idéia de permanência, ou seja, de que o falante tinha intenção de permanecer no local a que se referia o locativo, esse dado foi computado como [-permanência].

${ }^{11}$ Tendo em vista que os resultados foram categóricos para em relacionado ao traço [+permanência], Mollica opôs as preposições a e para, sendo possível perceber que quando a preposição para acompanha o verbo $i r$, a idéia de permanência está muito presente, contudo quando a preposição que acompanha esse verbo for $a$, a idéia de permanência está ausente. 
A terceira variável selecionada pelo programa foi a variável configuração do espaço, indicando que traços semânticos do locativo desempenham um papel na escolha da preposição que rege o verbo, como se pode ver nos resultados apresentados no quadro a seguir:

\begin{tabular}{|l|c|c|c|}
\hline & Aplic/total & $\mathbf{\%}$ & Peso relativo \\
\hline [+aberto] & $207 / 321$ & 64 & 0,58 \\
\hline [-aberto] & $91 / 209$ & 43 & 0,38 \\
\hline Total & $\mathbf{2 9 8 / 5 3 0}$ & $\mathbf{5 6}$ & \\
\hline \multicolumn{2}{|r|}{ Significância: 0.001} & Input: 0.573 \\
\hline
\end{tabular}

Quadro 3 - Configuração do espaço - valor de aplicação: preposição para

Os resultados do Quadro 3 indicam que o traço semântico [+aberto] favorece a escolha da preposição a/para, conforme depreende-se do peso relativo 0,58 . Já o traço semântico [-aberto] favorece a ocorrência de em como a preposição que rege o verbo, como aponta o peso relativo de 0,38 .

Esses resultados confirmam plenamente a tendência apontada por Mollica ${ }^{12}$ (1996) para o verbo $i$, indicando que esse traço semântico tem influência no comportamento dos verbos de movimento em geral. De acordo com a autora, a opção feita pela preposição em, quando o locativo tiver [-aberto] como traço semântico que o caracteriza, indica que ao valor de movimento acrescenta-se o valor "estar dentro". Cunha (1978) afirma que as preposições $a$, em e para tanto têm sentido de movimento quanto

${ }^{12}$ Os resultados também estão de acordo com os obtidos por Ribeiro (2008), que analisou a variação da regência do verbo ir na fala culta carioca. 
de situação. Em particular, a preposição em expressa sentido de posição no interior, dentro de limites. Por essa razão, se o traço semântico do locativo for [-aberto], há consonância entre preposição e locativo.

A última variável linguística selecionada pelo programa foi a variável grau de definitude e determinação do locativo. Os resultados são apresentados no Quadro 4, a seguir.

\begin{tabular}{|l|c|c|c|}
\hline & Aplic/total & $\mathbf{\%}$ & Peso relativo \\
\hline [+def./-det.] & $92 / 137$ & 67 & 0,69 \\
\hline [-def./-det.] & $75 / 104$ & $72^{13}$ & 0,57 \\
\hline [-def./+det.] & $48 / 101$ & 47 & 0,41 \\
\hline [+def./+det.] & $83 / 188$ & 44 & 0,39 \\
\hline Total & $\mathbf{2 9 8 / 5 3 0}$ & $\mathbf{5 6}$ & \\
\hline Significância: 0.001 & Input: 0.573 \\
\hline
\end{tabular}

Quadro 4 - Definitude e determinação do locativo - valor de aplicação: prep. para

Observa-se no quadro acima que o fato de o locativo referirse a um lugar conhecido ou facilmente identificável pelo falante e não ser acompanhado de um determinante, seja ele artigo ou pronome, contribui para a emergência da variante a/para. É o que indica o peso relativo 0,69 . Opostamente, quando o locativo vier acompanhado de um determinante e o lugar referido for conhecido do falante, a variante que tende a ocorrer é a com a preposição $\mathrm{em}$,

\footnotetext{
${ }^{13}$ Verifica-se neste quadro certo enviezamento dos resultados, já que ao maior peso relativo não corresponde a maior frequência. Tal enviezamento se explica em função do número reduzido de dados para os verbos levar e vir, o que acabou provocando a ocorrência de células vazias envolvendo essa variável.
} 
conforme o peso relativo 0,39 . Tais resultados assemelham-se parcialmente àqueles encontrados por Mollica (1996) e Ribeiro (2008) na análise do comportamento do verbo ir. A diferença fundamental está relacionada ao fato de que, em ambos os trabalhos, o que mais favoreceu a emergência de a/para foi a indeterminação do locativo e o seu referente não fazer parte do universo de conhecimento do falante. No presente trabalho, esse fator é o segundo em ordem de importância, conforme indica o peso relativo 0,57 . No entanto, os resultados aqui apresentados estão plenamente de acordo com os trabalhos desses autores no que se refere à variante em: quanto mais definido e mais conhecido for o referente do locativo maior possibilidade de emergir a preposição $\mathrm{em}$.

Por fim, a última variável a ser selecionada pelo programa e a única extralinguística foi a variável geográfica, que indicou que os falantes de Porto Alegre são os que mais usam verbos de movimento com a preposição a/para, enquanto os falantes de Florianópolis são os que mais usam a preposição $\mathrm{em}$. É o que se pode ver no quadro seguinte:

\begin{tabular}{|l|c|c|c|}
\hline & Aplic/total & $\mathbf{\%}$ & Peso relativo \\
\hline Porto Alegre & $136 / 213$ & 62 & 0,61 \\
\hline Curitiba & $59 / 105$ & 56 & 0,46 \\
\hline Florianópolis & $103 / 209$ & 49 & 0,40 \\
\hline Total & $\mathbf{2 9 8 / 5 3 0}$ & $\mathbf{5 6}$ & \\
\hline Significância: 0.001 & \multicolumn{2}{|c|}{ Input: 0.573} \\
\hline
\end{tabular}

Quadro 5 - Variável geográfica - valor de aplicação: preposição para

Observa-se no Quadro 5 que os falantes de Porto Alegre são os que mais utilizam a variante com a preposição a/para, conforme indica o peso relativo 0,61. Já os falantes de Florianópolis são os que menos utilizam essa variante (peso relativo: 0,40 ). Por 
fim, os dados mostram Curitiba com um peso relativo 0,46, indicando que, nessa amostra, a cidade tem um papel praticamente neutro em relação aos índices gerais de preservação ou substituição da preposição que rege o verbo de movimento.

\subsection{Resultados para o verbo "ir"}

Tendo em vista que na análise geral o verbo ir mostrou um comportamento claramente variável, decidiu-se fazer uma rodada somente com esse verbo, buscando verificar os fatores que condicionam a preservação ou a substituição da preposição que o rege. Para isso, foram utilizados os mesmo fatores avaliados para os verbos em geral. Com um percentual geral de $58 \%$, o programa selecionou os fatores [ \pm permanência], grau de definitude e de determinação e configuração do espaço como condicionadores da preservação da preposição a/para.

O quadro 6 mostra os resultados para a primeira variável selecionada.

\begin{tabular}{|l|c|c|c|}
\hline & Aplic/total & $\mathbf{\%}$ & Peso relativo \\
\hline [+ permanência] & $107 / 120$ & 89 & 0,84 \\
\hline [-permanência] & $122 / 271$ & 44 & 0,33 \\
\hline Total & $\mathbf{2 2 9 / 3 9 1}$ & $\mathbf{5 8}$ & \\
\hline Significância: 0.004 & \multicolumn{2}{|c|}{ Input: 0.631} \\
\hline
\end{tabular}

Quadro 6 - Traço semântico [permanência] - valor de aplicação: preposição para

Como se pode observar, o fator [ + permanência] revela-se fortemente condicionador da regência do verbo $i r$ com a preposição a/para, conforme se pode verificar pelo peso relativo 0,84 , já a ausência da ideia de permanência tende a inibir a escolha dessa preposição (peso relativo 0,33 ). Esses resultados estão em 
conformidade com aqueles encontrados por Mollica (1996) no que tange à preferência dos falantes pela preposição para quando houver a ideia de permanência. ${ }^{14}$ Apesar de no presente trabalho ter sido feita análise conjunta das preposições $a /$ para em oposição a em, esses resultados não invalidam a comparação feita com a pesquisa de Mollica (1996), já que o número de dados com a preposição $a$ foi extremamente reduzido. ${ }^{15}$

A segunda variável selecionada pelo programa como relevante na definição da preposição que rege o verbo ir é a variável grau de definitude e determinação do locativo.

\begin{tabular}{|l|c|c|c|}
\hline & Aplic/total & $\mathbf{\%}$ & Peso relativo \\
\hline [+def./-det.] & $66 / 84$ & 78 & 0,72 \\
\hline [-def./-det.] & $54 / 80$ & 67 & 0,55 \\
\hline [-def./+det.] & $41 / 86$ & 47 & 0,40 \\
\hline [+def./+det.] & $68 / 141$ & 47 & 0,39 \\
\hline Total & $\mathbf{2 2 9 / 3 9 1}$ & $\mathbf{5 8}$ & \\
\hline Significância: 0.004 & \multicolumn{2}{|c|}{ Input: 0.631} \\
\hline
\end{tabular}

Quadro 7 - Definitude e determinação do locativo - valor de aplicação: preposição para

Os resultados apresentados no Quadro 7 revelam, a princípio, que um alto grau de definição e de determinação do locativo favorece o uso da preposição em. É o que se pode concluir do peso relativo 0,39 . No entanto, o fator [-def/ +det.] apresentou um peso relativo praticamente igual, $0,40 . \mathrm{Na}$ análise conjunta dos

\footnotetext{
${ }^{14}$ Ver nota 10.

${ }^{15}$ Tal fato revela uma tendência na língua de substituição da preposição a por para ou em, o que já foi apontado por diversos autores, dentre eles, Pontes (1992) e Cunha (1976).
} 
verbos de movimento também foi obtido resultado semelhante. A dupla marca negativa apresentou peso relativo 0,55 , mostrando leve favorecimento para a ocorrência da preposição a/para, enquanto os locativos marcados pelos traços [+def./-det.] apresentaram peso relativo 0,72 , revelando alto favorecimento de a/para.

Nos resultados de Mollica (1996) e Ribeiro (2008), a dupla marca negativa e a positiva apresentaram probabilidades opostas, mínima e máxima, indicando que na amostra estudada tanto a presença/ausência de um determinante quanto o fato de o locativo ser conhecido/desconhecido do falante determinam a preposição que irá reger o verbo $i r$. No presente estudo, a partir dos resultados obtidos para o verbo $i$, mas também para os verbos de movimento rodados em conjunto, pode-se pensar que, na amostra analisada, é a presença ou ausência de um determinante o que define a preposição a ser escolhida: a ausência de determinante favorece o uso da preposição para, enquanto a presença de determinante, a da preposição $\mathrm{em}$.

A última variável selecionada pelo programa, apesar dos valores muito próximos do ponto neutro, foi a variável configuração do espaço, cujos resultados são apresentados a seguir.

\begin{tabular}{|l|c|c|c|}
\hline & Aplic/total & $\mathbf{\%}$ & Peso relativo \\
\hline [+aberto] & $164 / 258$ & 63 & 0,55 \\
\hline [-aberto] & $65 / 133$ & 48 & 0,41 \\
\hline Total & $\mathbf{2 2 9 / 3 9 1}$ & $\mathbf{5 8}$ & \\
\hline Significância: 0.004 & \multicolumn{2}{|c|}{ Input: 0.631} \\
\hline
\end{tabular}

Tabela 8 - Configuração do espaço - valor de aplicação: preposição para

De acordo com os resultados obtidos, quando o locativo referir-se a um lugar aberto, sem limites físicos, ou quando referir- 
se a um locativo abstrato, a preposição que mais frequentemente rege o verbo ir é a preposição para. É o que indica o peso relativo 0,55 . Contrariamente, um locativo que tenha como referente um lugar fechado, com limites físicos, tende a inibir a emergência da preposição a/para, conforme aponta o peso relativo 0,41 .

Esses resultados estão em perfeita consonância com os obtidos tanto por Mollica (1996) quanto por Ribeiro (2008) e também aproximam-se daqueles encontrados na análise feita para os verbos de movimento em geral. Uma explicação para esses resultados pode ser buscada em Travaglia (1985, p. 28), para quem a preposição é regida não só pelo verbo, mas também pelo seu argumento ou adjunto. Em consequência disso, a escolha da preposição se daria em dois níveis diferentes: no nível sintático, a preposição seria selecionada pelo verbo; no nível semântico, ela harmonizaria com o conteúdo semântico do adjunto ou do argumento do verbo.

\section{Considerações finais}

A partir do estudo realizado é possível tecer algumas considerações a respeito da regência dos verbos de movimento em geral e do verbo ir em particular. Em primeiro lugar, a exemplo do que já haviam concluído Mollica (1996) e Ribeiro (2008), podese dizer que o deslocamento da articulação verbo-preposição para verbo-locativo que vem ocorrendo no português brasileiro não representa uma variação livre, mas motivada por razões semânticas e, possivelmente, por razões pragmáticas. Portanto, há condicionamentos linguísticos e extralinguísticos atuando na seleção da preposição que rege os verbos de movimento. Em segundo lugar, a escolha de uma ou outra preposição está relacionada tanto a traços semânticos do locativo e do verbo quanto da preposição.

Especificamente em relação aos resultados encontrados, foi possível verificar que os verbos levar, vir e chegar apresentam pouca variação em sua regência: os dois primeiros, em geral, são regidos pela preposição a/para e o terceiro, regido pela preposição $\mathrm{em}$. $\mathrm{O}$ 
verbo ir, ao contrário, apresentou significativa variação, sendo a regência com a/para a variante preferida na amostra analisada.

Dos fatores linguísticos considerados, o traço semântico [ \pm permanência] foi a variável que se mostrou mais relevante na definição da preposição que irá reger o verbo: a presença da ideia de permanência favorece a emergência da preposição a/para, enquanto a ausência dessa idéia tende a inibir a ocorrência dessa preposição. Também mostraram-se relevantes na definição da preposição que rege os verbos de movimento em geral e o verbo ir em particular as variáveis grau de definitude e de determinação do locativo e configuração do espaço, revelando que a indeterminação do locativo e o fato de ter como referente um local [+aberto] favorecem a emergência da preposição a/para, já a determinação e definição do locativo e o fato de ter como referente um local [-aberto] condiciona o uso da preposição $\mathrm{em}$. Isso significa que a preposição que rege o verbo harmoniza-se semanticamente com o seu adjunto.

\section{Referências}

BISOL, Leda; BRESCANCINI, Cláudia. Fonologia e variação: recortes do português brasileiro. Porto Alegre: EDIPUCRS, 2002.

CÂMARA JR., Joaquim Mattoso. História e estrutura da Língua Portuguesa. Rio de Janeiro: Padrão, 1975.

CASTILHO, Ataliba. O problema da gramaticalização das preposições no projeto "Para a história do português brasileiro". Estudos lingüísticos, n. 33, p. 982-988, 2004.

CUNHA, Celso. Gramática do Português contemporâneo. Belo Horizonte: Bernardo Álvares, 1978.

FARIAS, Jair Gomes de. Variação entre a, para e em no português brasileiro e no português europeu: algumas notas. Letras de Hoje, v. 41, n. 1, p. 213-234, 2006. 
GONÇALVES, Perpétua. Para uma aproximação língualiteratura em português de Angola e Moçambique. v. 4. São Paulo: Via Atlântica, 2000. p. 212-213.

Aspectos da sintaxe do Português de Moçambique. In: FARIA, Isabel Hub; PEDRO, Emilia Ribeiro; DUARTE, Inês; GOUVEIA, A. M. Carlos. Introdução à lingüística geral e portuguesa. Lisboa: Caminho, 1996.

KLEPPA, Lou-Ann. Preposições ligadas a verbos na fala de uma criança em processo de aquisição de linguagem ou "Vamo de a pé no carro do vovô?". 2005. 186p. Dissertação (Mestrado em Linguística) - Universidade Estadual de Campinas, Campinas. Disponível em: <http://libdigi.unicamp.br>.

MOLLICA, Maria Cecília. A regência verbal do verbo ir em movimento. In: OLIVEIRA E SILVA, Giselle M.; SCHERE, Maria Marta P. (Orgs.). Padrões sociolingüísticos. Rio de Janeiro: Tempo Brasileiro, 1996. p. 85-119.

.; BRAGA, Maria Luíza (Orgs.). Introdução à sociolingüística: o tratamento da variação. São Paulo: Contexto, 2003.

PERINI-SANTOS, Pedro. Questionando a regularidade preposicional no português. Grupo in Cognito, 2004. Disponível em: <http://www.letras.ufmg.br/incognito/>.

PONTES, Eunice Souza Lima. Espaço e tempo na língua portuguesa. Campinas: Pontes, 1992. p. 11-34.

RIBEIRO, Antonio J. C. Variação e funcionalidade no uso de preposições e a regência do verbo ir na fala carioca. In: VOTRE, S.; RONCARATI, C. (Orgs.). Anthony Naro e a Lingüística no Brasil - uma homenagem acadêmica. Rio de Janeiro: 7Letras, 2008.

SILVA, Rosa Virgínia Mattos e. Estruturas trecentistas elementos para uma gramática do português arcaico. Rio de Janeiro: Imprensa Nacional; Casa da Moeda, 1989. 
TARALLO, Fernando. A pesquisa sociolingüística. 7. ed. São Paulo: Ática, 2001.

TRAVAGLIA, Luiz Carlos. Gramática e interação: uma proposta para o ensino de gramática. 9. ed. São Paulo: Cortez, 2003.

Sobre as possíveis razões da ausência e presença da preposição no OD. Letras e Letras, v. 1, n. 1, p. 15-39, 1985. 